\title{
Progress Towards Colorimetric and Fluorescent Detection of Carbonyl Sulfide
}

\author{
Matthew M. Cerda, ${ }^{\dagger}$ Julia M. Fehr, ${ }^{\dagger}$ Tobias J. Sherbow, ${ }^{\dagger}$ and Michael D. Pluth*
}

\begin{abstract}
We report here that a fluorescent benzobisimidazolium salt (TBBI) can be used for the fluorescent and colorimetric detection of carbonyl sulfide (COS) over related heterocumulenes including $\mathrm{CO}_{2}$ and $\mathrm{CS}_{2}$ in wet MeCN. The reaction between TBBI and COS in the presence of fluoride yields a highly fluorescent $\left(\lambda_{\mathrm{em}}=354 \mathrm{~nm}\right)$ and colored product $\left(\lambda_{\mathrm{ex}}=321 \mathrm{~nm}\right)$, that is readily observed by the naked eye. We view these results as a first step toward developing activity-based probes for COS detection.
\end{abstract}

Carbonyl sulfide (COS) is an important organosulfur species in the global sulfur cycle ${ }^{1}$ that is generated during the burning of biomass, ${ }^{2}, 3$ combustion of biofuels, ${ }^{4}$ and in different production processes in the pulp and paper industries. ${ }^{5}$ In addition, geochemical production of COS arises from volcanic activity, emission from hot springs, and deep sea thermal vents. ${ }^{6}$ Although the chemical properties and reactivity of COS have long been established, ${ }^{7}$ the biological implications of COS have only recently begun to emerge. ${ }^{8}$ As an example, treatment of $\alpha$-amino acids with $\operatorname{COS}$ under prebiotic reaction conditions results in the formation of dipeptides, demonstrating the potential role of COS in origin of life chemical ligation. ${ }^{9}$ Aligned with our interests in studying biological reactive sulfur species, ${ }^{10}$ our group has recently advanced the use of cos-releasing compounds for the controlled release of hydrogen sulfide $\left(\mathrm{H}_{2} \mathrm{~S}\right)$ due to the rapid catalyzed hydrolysis of COS by carbonic anhydrase, a ubiquitous metalloenzyme. ${ }^{11}$ Although enzymatic pathways for endogenous COS production in mammals remain undiscovered, COS has been detected in porcine cardiovascular tissues ${ }^{12}$ and exhaled breath from cystic fibrosis patients ${ }^{13}$ by using gas chromatography mass spectrometry. More recently, in our investigation of esterase-sensitive COS-based $\mathrm{H}_{2} \mathrm{~S}$ donors in human lung epithelial (BEAS2B) cells, we observed COSdependent inhibition of mitochondrial bioenergetics. This finding suggests that $\operatorname{COS}$ may possess biological activities and properties akin to $\mathrm{H}_{2} \mathrm{~S} .{ }^{14}$ As the potential roles of COS in biological systems and investigations into $\operatorname{COS}$ releasing compounds expand, a currently unmet need to further such investigations is the development of minimally invasive and sensitive methods for COS detection. Based on the significant impacts of colorimetric and fluorescent activity-based probes

\footnotetext{
a. Department of Chemistry and Biochemistry, Materials Science Institute, Knight Campus for Accelerating Scientific Impact, Institute of Molecular Biology, University of Oregon, Eugene, Oregon, 97403, USA. pluth@uoregon.edu

† These authors contributed equally
}

for the detection of reactive sulfur species, such as cysteine, reduced glutathione, and $\mathrm{H}_{2} \mathrm{~S}$, we envisioned that analogous platforms could be developed for COS detection. ${ }^{15,} 16$ To the best of our knowledge, no activity-based probes for COS detection or differentiation from the related heterocumulenes $\mathrm{CO}_{2}$ or $\mathrm{CS}_{2}$ have been reported.

(a)

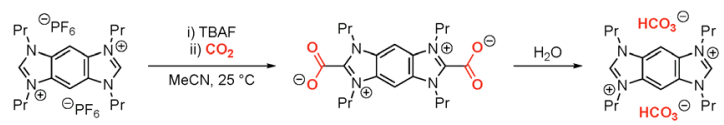

(b)

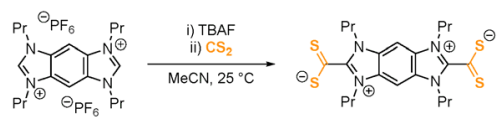

(c)

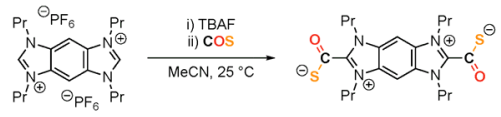

Figure 1. (a) Reaction of $\mathrm{CO}_{2}$ and TBBI in the presence of fluoride. (b) Reaction between $\mathrm{CS}_{2}$ and TBBI in the presence of fluoride. (c) Proposed reaction between $C O S$ and $T B B I$ in the presence of fluoride.

Based on the electrophilicity and structural similarities between carbon dioxide $\left(\mathrm{CO}_{2}\right)$, carbon disulfide $\left(\mathrm{CS}_{2}\right)$, and $\mathrm{COS},{ }^{7}$ we anticipated that a nucleophilic platform could be used to develop chemical tools for cos detection. For example, $\mathrm{N}$ heterocyclic carbenes can insert into heterocumulenes, which has been demonstrated separately for $\mathrm{CO}_{2},{ }^{17} \mathrm{CS}_{2},{ }^{18}$ and $\mathrm{COS},{ }^{19}$ respectively. Bridging the gap to heterocumulene detection, the vast majority of work has aimed at the spectroscopic ${ }^{20}$ or electrochemical detection ${ }^{21}$ of $\mathrm{CO}_{2}$. Of these reported methods, we were drawn to the prior use of a fluorescent, colorimetric benzobisimidazolium probe (TBBI) for $\mathrm{CO}_{2}$ detection. ${ }^{22}$ In this system, treatment of TBBI with tetra- $n$-butylammonium fluoride (TBAF) produces a "carbene-like" intermediate ${ }^{23}$ that readily reacts with $\mathrm{CO}_{2}$ through carbene insertion into $\mathrm{CO}_{2}$ and subsequent hydrolysis to form bicarbonate (Figure 1a). This reactivity was also investigated for $\mathrm{CS}_{2}$ by ${ }^{13} \mathrm{C}$ NMR spectroscopy and shown to result in the generation of an imidazoliumdithiocarboxylate betaine through carbene insertion into $\mathrm{CS}_{2}$ (Figure 1b). Building from structural similarities between these compounds, we hypothesized the treatment of TBBI with COS in the presence of fluoride would provide a unique 
spectroscopic response for $\mathrm{COS}$ that would be distinguishable from that of $\mathrm{CO}_{2}$ and $\mathrm{CS}_{2}$. Based on this motivation, we report here the first demonstration of selective COS detection by UVVis and fluorescence spectroscopy.

One challenge when working with $\mathrm{COS}$ is that commercial sources often contain $\mathrm{H}_{2} \mathrm{~S}$ as a common impurity. To overcome this challenge, we prepared COS through the acidic hydrolysis of KSCN using modifications of known methods (Figure 2a). ${ }^{24}$ Based on the growing interest in various aspects of COS chemistry, including delivery, organometallic chemistry, and chemical biology, we have included this method here and in the Supporting Information. A key requirement when preparing COS is purification of the product, which can be accomplished by sparging through aqueous $\mathrm{KOH}$, aniline in anhydrous ethanol, ice water, and neat $\mathrm{H}_{2} \mathrm{SO}_{4}$. The purified $\mathrm{COS}$ can be collected and stored in a gas storage flask or added directly into a solution or NMR tube for use as a reactant or reagent (Figure 2b). $\operatorname{COS}$ has a characteristic ${ }^{13} \mathrm{C}$ chemical shift at $\delta=154.3 \mathrm{ppm}$ $\left(\mathrm{CD}_{3} \mathrm{CN}\right)$ and IR stretch at 2927 and $2909 \mathrm{~cm}^{-1}$, which match prior reports. ${ }^{25}$

(a)

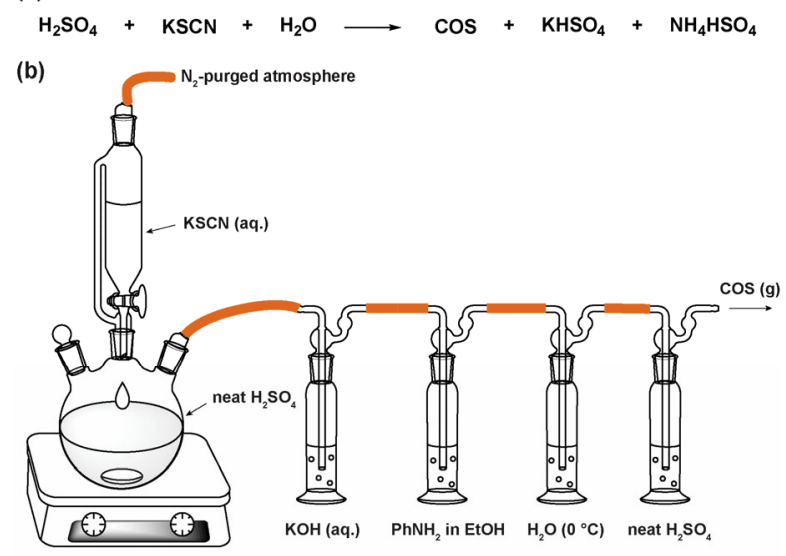

Figure 2. (a) Acid-mediated hydrolysis of $\mathrm{KSCN}$ to generate COS. (b) Schematic of laboratory-scale COS synthesis and purification.

To investigate the proposed strategy of carbene insertion for COS detection, we prepared $\mathrm{TBB}^{22}$ and monitored its reactivity toward COS in the presence of TBAF by UV-Vis spectroscopy (Figure 3a). The parent TBBI compound (15 $\mu \mathrm{M}$ in MeCN containing $\left.1 \%(\mathrm{v} / \mathrm{v}) \mathrm{H}_{2} \mathrm{O}\right)$ has an absorption band centered at $290 \mathrm{~nm}$, which shifts to $344 \mathrm{~nm}$ upon addition of TBAF (6.0 equiv.). This change in absorbance is consistent with the previous report of hydrogen bond formation between the $\mathrm{C} 1-\mathrm{H}$ in TBBI and $\mathrm{F}^{-} .22$ Subsequent addition of COS in $0.5 \mathrm{~mL}$ increments resulted in a decrease in the $344 \mathrm{~nm}$ absorbance and concomitant increase of a new absorbance at $321 \mathrm{~nm}$. We note that this observed reaction with $\mathrm{COS}$ did not occur if anhydrous $\mathrm{MeCN}$ was used, which highlights that residual $\mathrm{H}_{2} \mathrm{O}$ is required. The new absorbance at $321 \mathrm{~nm}$ is unique to $\mathrm{COS}$ and is not observed upon reaction of TBBI with $\mathrm{CO}_{2}$ or $\mathrm{CS}_{2}$ in the presence of TBAF. (a)

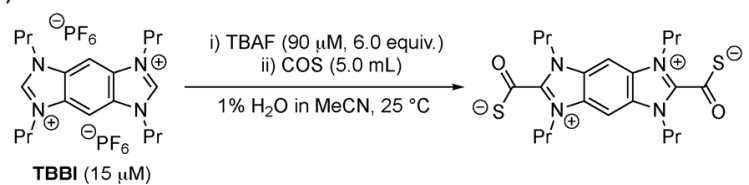

(b)

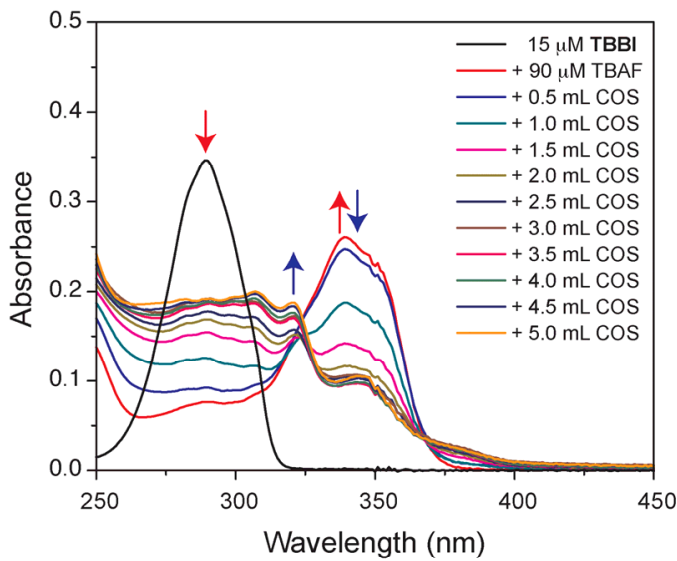

(c)

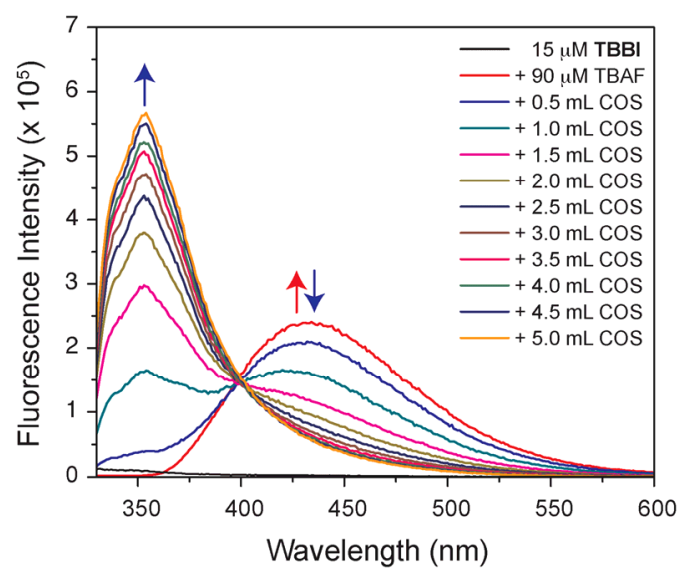

Figure 3. (a) Reaction of TBBI with COS. (b) UV-Vis spectra and (c) fluorescence spectra for TBBI $(15 \mu \mathrm{M}), \operatorname{TBAF}(90 \mu \mathrm{M})$, and $\operatorname{COS}(5.0 \mathrm{~mL})$.

Building from this observation, we next investigated the reaction by fluorescence spectroscopy. The parent TBBI compound (15 $\mu \mathrm{M}, \mathrm{MeCN}$ containing $1 \%(\mathrm{v} / \mathrm{v}) \mathrm{H}_{2} \mathrm{O}$ ) showed negligible fluorescence when excited at $321 \mathrm{~nm}$, but addition of TBAF (6.0 equiv.) resulted in the appearance of a broad emission centered at $434 \mathrm{~nm}$, which we attribute to formation of the hydrogen bonded TBBI intermediate. Subsequent addition of COS in $0.5 \mathrm{~mL}$ increments led to a clean ratiometric response, with a decrease at the $434 \mathrm{~nm}$ emission and concomitant increase at $354 \mathrm{~nm}$ (Figure 3c). The product formed upon COS addition is persistent, unlike in the case for $\mathrm{CO}_{2}$ in which rapid hydrolysis to bicarbonate is observed. A plot of COS concentrations against the ratio of fluorescence intensities at 354 and $434 \mathrm{~nm}$ is linear $\left(R^{2}=0.986\right)$, which suggests that this detection method could be used to quantify $\operatorname{COS}$ concentrations (see Supporting Information). Taken together, these results demonstrate that TBBI can be used to spectroscopically distinguish between $\mathrm{CO}_{2}, \mathrm{CS}_{2}$, and $\mathrm{COS}$ in the presence of the fluoride. 
To confirm the formation of the proposed thiocarboxylate product, we accessed this compound by treatment of TBBI with KHMDS (2.2 equiv.) and subsequent addition of $\operatorname{COS~(g).~The~}$ addition of $\operatorname{COS}(\mathrm{g})$ to a solution of doubly deprotonated TBBI in THF- $\mathrm{d}_{8}$ yielded a yellow-orange solution and the appearance of a new resonance in the ${ }^{13} \mathrm{C}$ NMR spectrum at $190.34 \mathrm{ppm}$ corresponding to thiocarboxylate formation (Figure $4 a$ and $b$ ). This observed chemical shift is within the range of previously synthesized imidazolium-2-thiocarboxylates. ${ }^{19}$ We further characterized this compound by IR spectroscopy and observed $\mathrm{C}-\mathrm{S}$ and $\mathrm{C}=\mathrm{O}$ stretching frequencies at 990 and $1524 \mathrm{~cm}^{-1}$, respectively (see Supporting Information). We next measured the fluorescence spectrum of this product in MeCN $\left(\lambda_{\mathrm{ex}}=321\right.$ $\mathrm{nm}, \lambda_{\mathrm{em}}=330-600 \mathrm{~nm}$ ) and observed a nearly identical match to the spectroscopic properties observed under experimental conditions (Figure 4c). When taken together, the combined ${ }^{13} \mathrm{C}$ NMR data and fluorescence spectroscopy data both support the formation of the proposed thiocarboxylate upon treatment of TBBI with $\mathrm{F}^{-}$and $\operatorname{COS}(\mathrm{g})$.

(a)
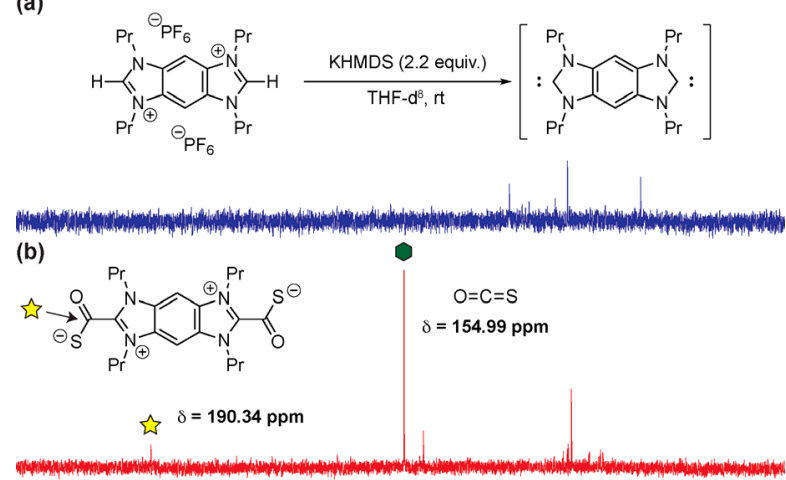

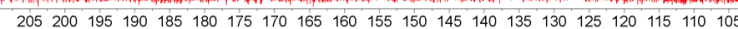

(c)

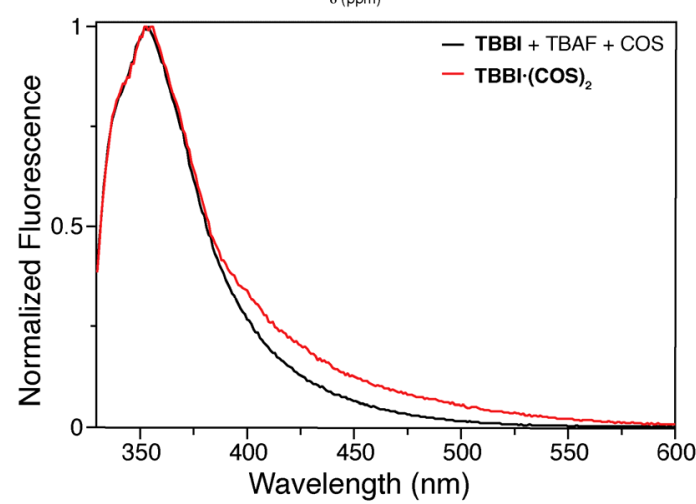

Figure 4. (a) The ${ }^{13} \mathrm{C}\left\{{ }^{1} \mathrm{H}\right\}$ NMR spectrum of TBBI (30 mM) treated with KHMDS (2.2 equiv.) in THF- $d^{8}$. (b) The ${ }^{13} \mathrm{C}\left\{{ }^{1} \mathrm{H}\right\}$ NMR spectrum following the addition of $\operatorname{COS}(\mathrm{g})$ to a solution of doubly deprotonated TBBI. (c) Normalized fluorescence spectra comparing emission from TBBI + TBAF + COS and the synthesized thiocarboxylate adduct (TBBI·(COS) 2 ).

The stability and unique spectroscopic properties of product formed upon COS addition prompted us to investigate whether this TBBI system could be used for naked-eye optical detection of COS. The recognition of $\mathrm{CS}_{2}$ by $10 \mathrm{mM}$ TBBI in the presence of fluoride was previously reported to generate a color change from clear to yellow red and form an imidazoliumdithiocarboxylate betaine. ${ }^{22}$ To further investigate this reactivity, we charged a series of cuvettes with $10 \mathrm{mM}$ TBBI and $60 \mathrm{mM}$ TBAF in MeCN containing $1 \%(\mathrm{v} / \mathrm{v}) \mathrm{H}_{2} \mathrm{O}$ to generate the hydrogen bonded intermediate; this was followed by addition of $\mathrm{CO}_{2}, \mathrm{CS}_{2}$, or $\mathrm{COS}$ (Figure 5). Consistent with previous results, the cuvette containing $\mathrm{CO}_{2}$ yielded a white precipitate corresponding to the bicarbonate salt of TBBI, whereas the cuvette containing $\mathrm{CS}_{2}$ yielded a pale orange solution. The reaction between TBBI and COS yielded a teal green color and transitioned to a dark forest green upon standing for an extended period of time. These results demonstrate the unique ability of TBBI to serve as a versatile platform for distinct recognition of $\mathrm{CO}_{2}, \mathrm{COS}$, and $\mathrm{CS}_{2}$ by naked eye detection.

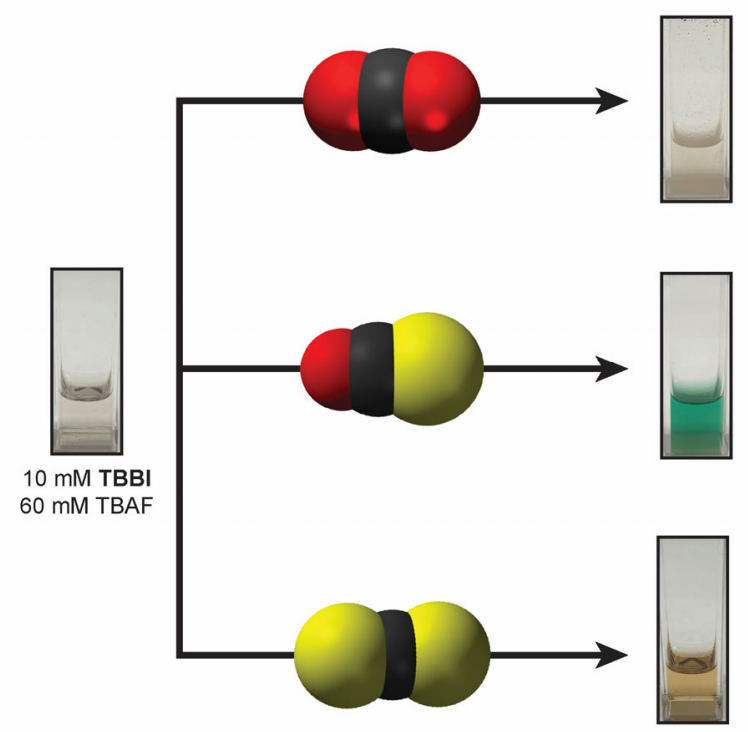

Figure 5. Naked-eye detection and differentiation of $\mathrm{CO}_{2}, \mathrm{CS}_{2}$, and $\mathrm{COS}$ using TBBI $(10 \mathrm{mM})$ in the presence of TBAF $(60 \mathrm{mM})$.

In summary, we have demonstrated that the TBBI platform can be used for the colorimetric and fluorescent detection of COS. Importantly, these spectroscopic responses for COS are distinct from those generated by $\mathrm{CO}_{2}$ or $\mathrm{CS}_{2}$. We view that these advances provide a first step toward developing activity-based chemical tools for COS detection and imaging, which we anticipate can be used to investigate the growing evidence for a biological role of COS in complex environments.

\section{Conflicts of interest}

There are no conflicts to declare.

\section{Acknowledgements}

This research was supported by the NIH (R01GM113030). NMR instrumentation in the UO CAMCOR facility is supported by the NSF (CHE-1427987 and CHE-1625529). 


\section{References}

1. C.-L. Lee and P. Brimblecombe, Earth Sci Rev, 2016, 160, 1-18.

2. M. O. Andreae and P. Merlet, Global Biogeochem Cycles, 2001, 15, 955-966.

3. M. O. Andreae, Atmos Chem Phys, 2019, 19, 8523-8546.

4. J. E. Campbell, M. E. Whelan, U. Seibt, S. J. Smith, J. A. Berry and

T. W. Hilton, Geophys Res Lett, 2015, 42, 3004-3010.

5. E. Vainio, A. Brink, N. Demartini, M. Hupa, H. Vesala, K. Tormonen and T. Kajolinna, J. Pulp Pap. Sci., 2010, 36, 135-142.

6. S. F. Watts, Atmos Environ, 2000, 34, 761-779.

7. R. J. Ferm, Chem Rev, 1957, 57, 621-640.

8. A. K. Steiger, Y. Zhao and M. D. Pluth, Antioxid Redox Signal, 2018, 28, 1516-1532.

9. L. Leman, L. Orgel and M. R. Ghadiri, Science, 2004, 306, 283286.

10. N. Lau and M. D. Pluth, Curr Opin Chem Biol, 2019, 49, 1-8.

11. C. M. Levinn, M. M. Cerda and M. D. Pluth, Acc Chem Res, 2019, 52, 2723-2731.

12. M. Balazy, I. A. Abu-Yousef, D. N. Harpp and J. Park, Biochem Biophys Res Commun, 2003, 311, 728-734.

13. M. A. Kamboures, D. R. Blake, D. M. Cooper, R. L. Newcomb, M. Barker, J. K. Larson, S. Meinardi, E. Nussbaum and F. S. Rowland, Proc Natl Acad Sci U S A, 2005, 102, 15762-15767.

14. A. K. Steiger, M. Marcatti, C. Szabo, B. Szczesny and M. D. Pluth, ACS Chem Biol, 2017, 12, 2117-2123.

15. J. Zhou and H. Ma, Chem Sci, 2016, 7, 6309-6315.

16. X. Jiao, Y. Li, J. Niu, X. Xie, X. Wang and B. Tang, Anal Chem, 2018, 90, 533-555.

17. A. Tudose, A. Demonceau and L. Delaude, Journal of Organometallic Chemistry, 2006, 691, 5356-5365.

18. L. Delaude, A. Demonceau and J. Wouters, Eur J Inorg Chem, 2009, 2009, 1882-1891.

19. M. Hans, J. Wouters, A. Demonceau and L. Delaude, Eur J Org Chem, 2011, 2011, 7083-7091.

20. X. Zhou, S. Lee, Z. Xu and J. Yoon, Chem Rev, 2015, 115, 79448000.

21. S. Neethirajan, D. S. Jayas and S. Sadistap, Food Bioprocess Tech, 2008, 2, 115-121.

22. Z. Guo, N. R. Song, J. H. Moon, M. Kim, E. J. Jun, J. Choi, J. Y. Lee, C. W. Bielawski, J. L. Sessler and J. Yoon, J Am Chem Soc, 2012, 134, 17846-17849.

23. M. N. Hopkinson, C. Richter, M. Schedler and F. Glorius, Nature, 2014, 510, 485-496.

24. P. D. N. Svoronos and T. J. Bruno, Indust Eng Chem Res, 2002, 41, 5321-5336.

25. C.-J. Zhang and X.-H. Zhang, Macromolecules, 2019, 53, 233-

239. 


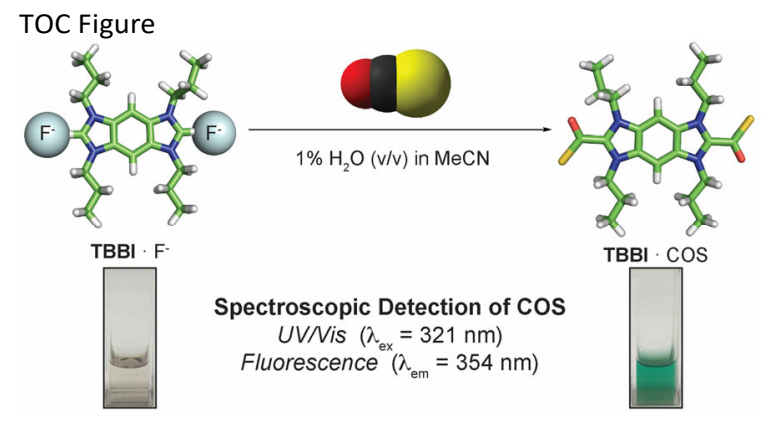

